\title{
Neuroprotective Potential of Lantana Trifolium Ethanolic Extract against Ethambutol Induced Histological Changes in the Optic Nerve
}

Owembabazi Elna ${ }^{1 *}$, Ninsiima Herbert Izo², Mario Edgar Fernandez Diaz ${ }^{1}$, Echoru Isaac ${ }^{1}$, Lemuel Ann Monima ${ }^{1}$, Ahimbisibwe James $^{1}$, Bukenya Edmund ${ }^{1}$

${ }^{1}$ Department of Anatomy, Kampala International University-Western Campus, P.O. Box 71 Ishaka Bushenyi, Uganda.

${ }^{2}$ Department of Physiology, Kampala International University-Western Campus, P.O.Box 71 Ishaka Bushenyi, Uganda.

Correspondence to Owembabazi Elna, Kampala International University-Western Campus P.O.Box 71 Ishaka Bushenyi-Uganda, +256703640027, lenaoet@gmail.com

\begin{abstract}
Ethambutol is an anti-tuberculosis drug important in treatment of multidrug resistant tuberculosis which is on a rise due to emergence of Human Immunodeficiency Virus. However, it has been associated with side effects on optic nerve histology leading to severe neuropathy. The purpose of this study was to establish the protective potential of Lantana trifolium ethanolic extract against ethambutol induced histological changes in the optic nerve. Twenty five male adult wistar rats of $110-130 \mathrm{~g}$ average weight were used. These were divided into five groups each comprising five animals. Group A received distilled water only. Group B was treated with $100 \mathrm{mg} / \mathrm{kg} /$ day of ethambutol. Groups C, D, and E were treated with 25, 50, and $100 \mathrm{mg} / \mathrm{kg} /$ day of Trifolium Extract respectively, one hour before administering $100 \mathrm{mg} / \mathrm{kg} /$ day of ethambutol. After five weeks the optic nerves were excised, processed and stained for histological studies. It was observed that Lantana trifolium ethanolic extract had a dose dependent protective potential against ethambutol induced histological changes in the optic nerve. The histology of the optic nerve showed that the numbers of vacuoles were significantly few in group $A$ (2.2 \pm 0.37$), D(6.2 \pm 1.07)$, and $E(5 \pm 0.71)$ when compared against the positive control group (37.4 \pm 1.54$)$. Axons were mildly demyelinated in group $D$ and $E$ compared to group $B$ and $C$. The protective potential of Latana trifolium is possibly present due to its anti-oxidative and antiinflammatory activities. Studies to determine the exact phytochemical component and mechanism of action responsible for the neuroprotective potential of Latana trifolium should be conducted.
\end{abstract}

Key Words: Ethambutol, Optic Nerve, Lantana Trifolium, Optic Neuropathy.

\section{INTRODUCTION}

Ethambutol (EMB) is one of the first line drugs for treating tuberculosis (TB) (Biadglegne et al., 2014) [1]. It broadens the resistance spectrum and prevents development of resistance to companion drugs (Lacoma et al., 2015) [2]. Regardless of these desirable characteristics, EMB is known to cause histological changes in the optic nerve that result into optic neuropathy (Wang et al., 2012) [3]. This was established soon after its discovery in 1960 s as a promising agent to treat tuberculosis (Forbes et al., 1962) [4]. Ethambutol induced optic neuropathy is classically described as reversible on discontinuation with complete recovery over period of weeks to months (Holla at al., 2015) [5]. However worsening of vision after EMB discontinuation is also documented (Garg et al., 2015) [6]. There are reports of some patients 
who develop severe, irreversible visual impairment despite frequent monitoring and standard dosages (Chen et al., 2015) [7]. Worldwide 100,000 people are estimated to lose vision completely each year due to the use of EMB (Bourne et al., 2013) [8]. This number may increase due to prolonged use of anti TB drugs in HIV/AIDs patients and those with relapses.

The exact mechanism of how EMB induces optic neuropathy has not been confirmed (Palomino and Martin, 2014) [9]. However it has been stipulated that it is due to the chelating effects of EMB and its metabolites that interfere with several mitochondrial metal containing enzymes (Rasool et al., 2015) [10]. This causes interruption of mitochondrial function and oxidative phosphorylation that result into optic nerve damage (Kinoshita et al., 2012) [11]. The symptoms of EMB induced toxic optic neuropathy are painless, symmetrical and progressive (Rasool et al., 2015) [10]. The condition is underdiagnosed and the diagnosis is mostly done when recovery of vision is impossible (Jeanjean and Dupeyron, 2014) [12]. Moreover there are no preventive and treatment measures for EMB induced optic neuropathy up to date (Yang et al., 2016) [13].
It is therefore necessary that studies to find a remedy for the toxic effects of EMB are carried out, of which Lantana trifolium leaf extract can be one of the remedies.

Lantana trifolium known as Kayukiyuki (Luganda), Omuhuuki (Runyankore) belongs to the family of Verbenaceae (Nalubega et al., 2011) [14]. It is a three leafed, scrambling, evergreen shrub growing up to 3 meters tall in all subtropical and tropical regions (Schemske, 1976) [15]. In Uganda, leaves of Lantana trifolium have been used to treat eye conditions such as blindness, glaucoma, conjunctivitis, and bacterial and viral eye infection (Ocheng et al., 2014) [16]. Previous studies have reported that Lantana trifolium extract has anti-oxidative, anti-inflammatory, anti-nociceptive and sedative activity in experimental animals (Silva et al., 2005) [17]. The few studies that have been carried out on the chemistry of Lantana trifolium show that its biological activities are associated with its components mainly the phenols, phenylpropanoids, flavonoids and terpenoids (Imbenzi et al., 2014) [18]. The aim of this study was to establish the neuroprotective potential of Lantana trifolium ethanolic extract against ethambutol induced histological changes in the optic nerve.

\section{MATERIALS AND METHODS}

\section{Animals}

This experimental design involved 25 male adult wistar rats of $110-130 \mathrm{~g}$ average weight. These were obtained from the animal facility at Kampala International University (KIU). They were housed in cages, exposed to 12 hour of dark and light cycles. They were fed on commercial rat pellets (Nuvita Feeds- Kampala, Uganda) and provided with tap water ad libitum. Animals were randomly divided into five groups of five rats each. Group A, the negative control group received distilled water. Group B, the positive control group received EMB at dose of $100 \mathrm{mg} \backslash \mathrm{kg} \backslash$ day orally for five weeks. Groups C, D and E received Lantana trifolium ethanolic extract at doses of $25 \mathrm{mg} \backslash \mathrm{kg} \backslash$ day, $50 \mathrm{mg} \backslash \mathrm{kg} \backslash$ day and $100 \mathrm{mg} \backslash \mathrm{kg} \backslash$ day orally respectively one hour before orally receiving EMB at doses of $100 \mathrm{mg} \backslash \mathrm{kg} \backslash$ day for five weeks.

\section{Ethical Considerations}

This study was approved by the Directorate of Postgraduate Studies and Research of Kampala International University Western Campus. All animal studies that were carried out in this experiment were conducted in accordance with "Guide for Care and use of Laboratory Animals" (National Research Council, 2010) [19]. A minimum number of animals were used in the study and inflicting pain to the animals was minimized by sacrificing them under anaesthesia. EMB toxicity is not contagious, thus experimental animals were not harmful to people and environment. 


\section{Plant}

Leaves of the plant were collected early in the morning and packed in a black polythene bag, from Bushenyi district in western Uganda. A sample of the fresh and a shade dried plant was taken to Makerere University Herbarium for identification by a Botanical Taxonomist Dr. Mary Namaganda. It was identified as Lantana trifolium and given a collector number $\mathrm{OE}$ $\# 001$. A sample of this was kept for future references.

\section{Preparation of the Extract}

The leaves were properly washed with tap water before shade drying, and then ground using a motor and pestle. The powdered material was put in the thimble and loaded into a Soxhlet apparatus for ethanolic extraction at a temperature of $80{ }^{\circ} \mathrm{C}$ (Luque-decastro and Priego-capote, 2010) [20]. The extract was filtered through a watmann filter paper (125 $\mathrm{mm}$ ) and concentrated using a rotary evaporator maintained at $40{ }^{\circ} \mathrm{C}$. Using a water bath, the concentrated extract was evaporated to dryness and stored in a refrigerator at $4^{\circ} \mathrm{C}$.

\section{Administration of Ethambutol and} Lantana Trifolium Ethanolic Extract

Ethambutol (Cosmos Limited- Nairobi, Kenya) and plant extract were each dissolved in distilled water and then administered once daily using oral gavage. Ethambutol was administered one hour after Lantana trifolium administration. The dose of EMB and plant extract given to each of the animals was calculated using the standard formula below.

Dose given $=$ dose $(\mathrm{mg} / \mathrm{kg}) \times$ animal weight $(\mathrm{g})$ Concentration $(\mathrm{mg} / \mathrm{ml}) \times 1000$.

(Ninsiima et al., 2016) [21].

\section{Histological analysis of the optic nerve}

The animals were deeply anesthetized by placing them in a transparent air tight container having cotton soaked with $1.9 \%$ of ether. An incision was made in the skin overlying cervical region when the animals were unconscious. Using surgical blade, forceps and scissors for dissection the scalp was removed exposing the skull cap. This was detached from the dura mater and the calvarium lifted to expose the brain. The falx cerebri was pulled posteriorly, away from the crista galli. The frontal lobes were raised from the anterior cranial fossa, incised and removed to expose the optic nerves along with the chiasma (Heffner et al., 1980) [22]. Both optic nerves were cleanly dissected (fig. 1), incised proximal to the optic chiasma and then removed along with the eye balls. They were fixed immediately with $4 \%$ paraformaldehyde in phosphate buffer saline (PBS). Tissues were post fixed in $2 \%$ osmium tetroxide in PBS for 2 hours. These were then processed for histological examination using an automated tissue processor (Histokinette-SLEE MAINZ, MTP type). After which they were placed vertically in the center of embedding moulds and molten paraffin wax was used for embedding. Sections of $10 \mu \mathrm{m}$ and $3 \mu \mathrm{m}$ thickness were cut from the cold tissue blocks using a rotatory microtome (SLEE MAINZ, CUT4062 model) and stained using Luxol fast blue (LFB) stain, Hematoxlyin and Eosin respectively (Kiernan et al., 2010) [23]. The slides were examined under a light microscope (Nikon Eclipse Ci, 104C type) using X40 objective and the observations recorded. Photomicrographs were taken using a mounted digital camera (Nikon digital sight DS, Fi 1) attached to a computer with software (NISElements F3.00, SP7; Build 547).

\section{Data Analysis}

The number of vacuoles observed in the photomicrographs were counted using Image] 2015 (Fiji). Using graph pad prisms V6, mean \pm SEM were obtained for the number of vacuoles, and then analysis of variance (ANOVA) was applied to determine group mean differences between the control and test groups. A postHOC Tuckey test was used to determine differences in group means considering a pvalue of $<0.05$ to be statistically significant. 


\section{RESULTS}

In this study trifolium extract (TE) showed a dose dependent protective effect. Varying numbers of vacuoles were observed in the optic nerves of all the groups (fig. 2). The number of vacuoles in positive control group (37.4 11.54$)$ and; the group that received EMB and $25 \mathrm{mg} / \mathrm{kg}$ TE $(36 \pm 1.30)$ were significantly high $(P<0.05)$ when compared to the number of vacuoles in the negative control group (2.2 \pm 0.37$)$. The number of vacuoles in the groups treated with EMB and $50 \mathrm{mg} / \mathrm{kg}$ TE $(6.2 \pm 1.07)$ and; EMB and $100 \mathrm{mg} / \mathrm{kg}$ TE $(5 \pm 0.71)$ were significantly few $(P<0.05)$ when compared to those in the positive control group. Demyelination was not observed in the optic nerve axons of the negative control group (fig. 6). However varying degrees of demyelination were observed in the remaining groups. Axonal demyelination was severe in the axons of the optic nerves of the positive control group and; the group treated with $\mathrm{EMB}$ and $25 \mathrm{mg} / \mathrm{kg} \mathrm{TE}$ (fig. 7). Axonal demyelination was mild in the groups treated with EMB and $50 \mathrm{mg} / \mathrm{kg}$ TE and; EMB and $100 \mathrm{mg} / \mathrm{kg}$ TE (fig. 8).

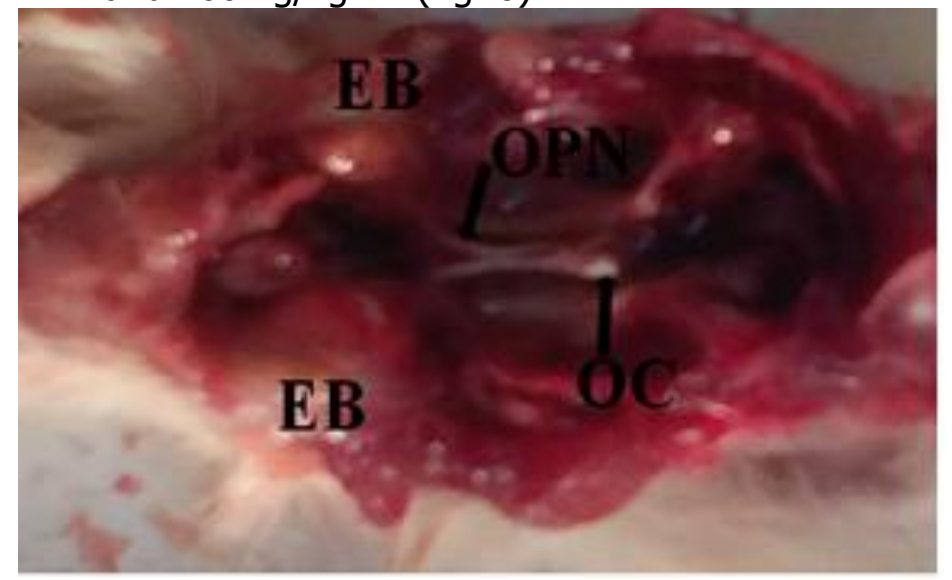

Figure 1: Photograph Showing the Eye Ball (EB), and Arrows Pointing at Optic Nerve (OPN) and Optic Chiasma (OC) in Situ after Removing the Brain.

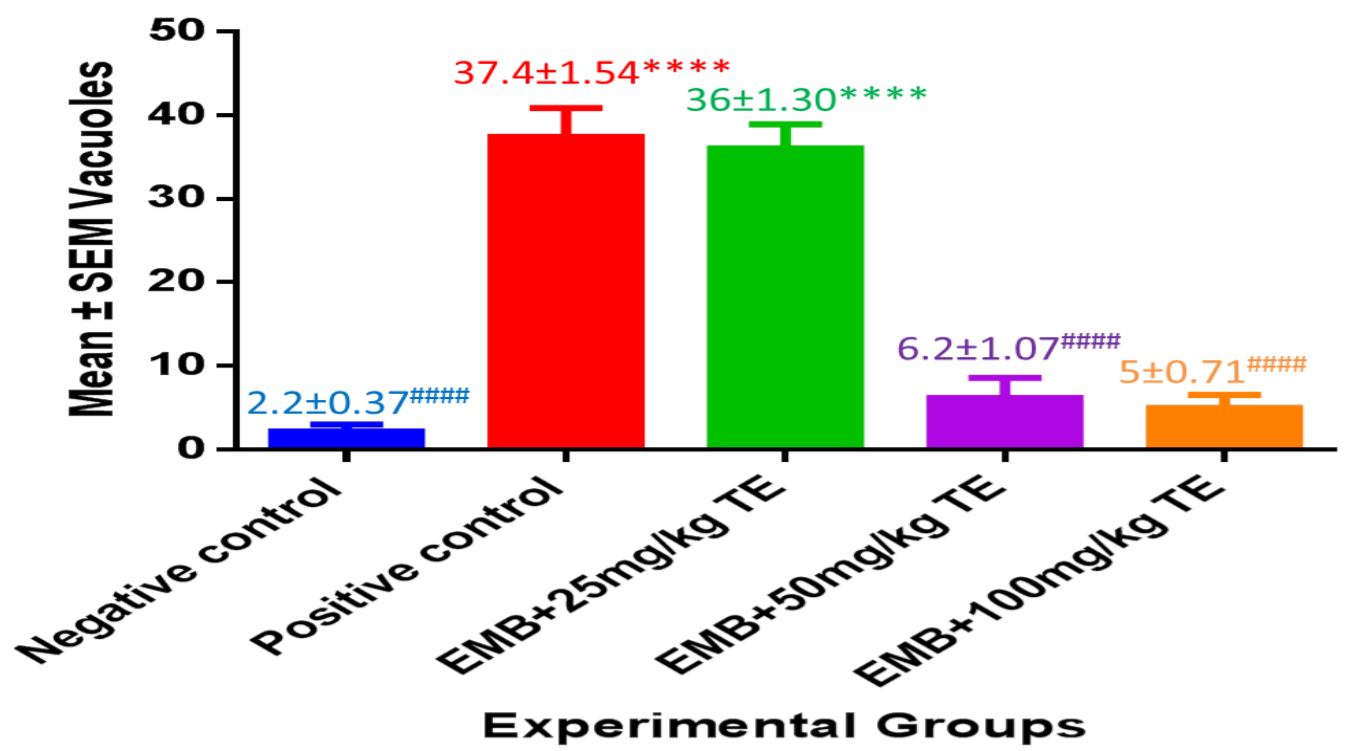

Figure 2: A Bar Graph Showing Number of Vacuoles in the Optic Nerve Cross Section. EMB = Ethambutol; TE = Trifolium Extract. Multiple comparisons; against the negative control group $* * * * \mathrm{P}<0.0001$; against positive control group, \#\#\#\# <0.0001.

\section{DISCUSSION}

Latana trifolium extract had a dose dependent neuroprotective potential against EMB induced histological changes in the optic nerve. The extract showed a dose dependent protection against optic nerve vacuolation and axonal demyelination. In this study vacuoles were observed in the optic nerves of all the groups.
However there were significant differences in the number of vacuoles from the different groups (fig. 3, 4 \& 5). The few vacuoles observed in the negative control group are as a result of apoptosis (Sadun, 2012) [24]. The highest 

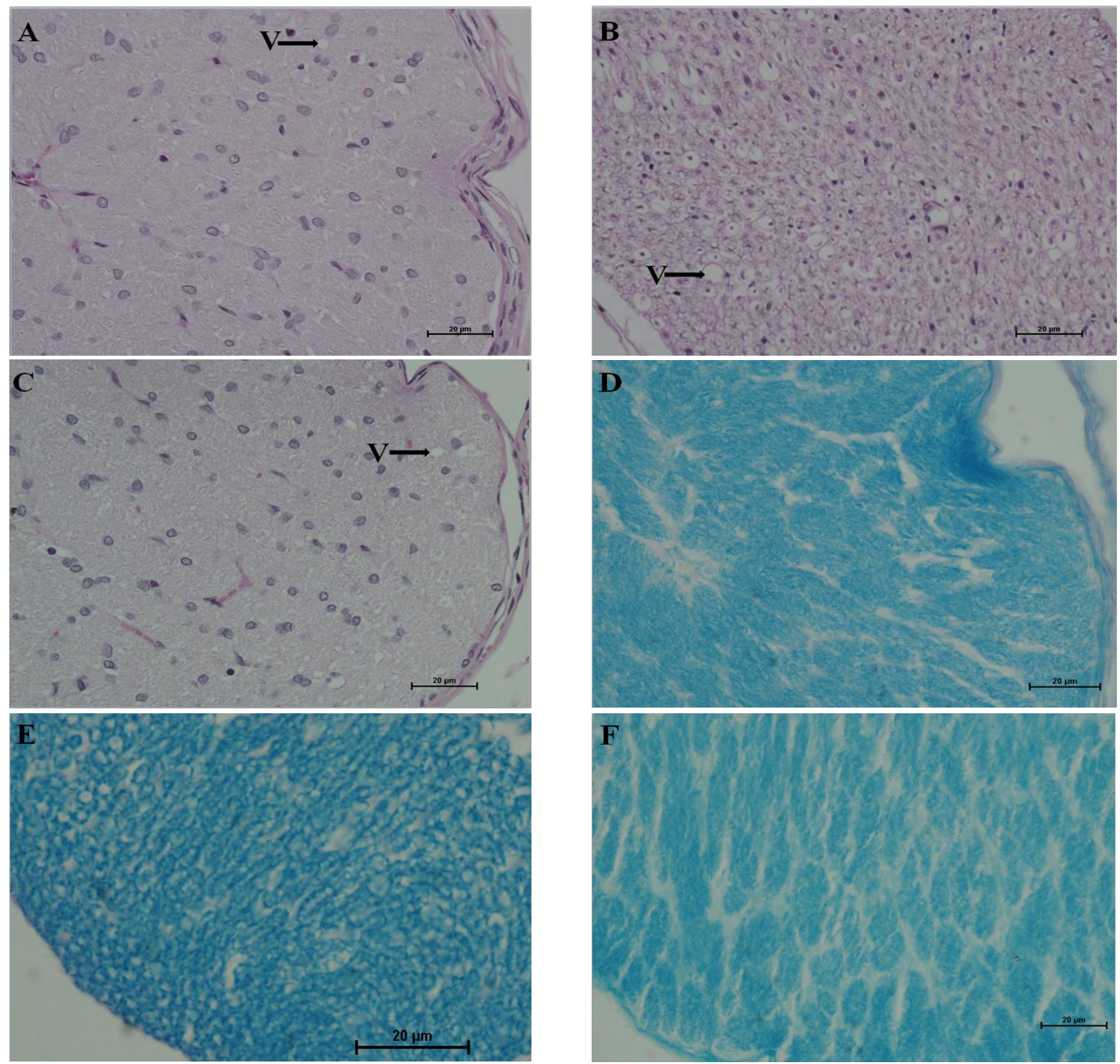

A: Photomicrographs of Optic Nerve Cross Section from Group A Showing a few Vacuoles (V). H \& E Stain, X40. B: Photomicrographs of Optic Nerve Cross Section from group B Showing Many Vacuoles (V). H \& E Stain, X40. C: Photomicrographs of Optic Nerve Cross Section from Group E Showing a Few Vacuoles (V) Comparable to Those in Group A. H \& E Stain, X40. D: Photomicrographs of Optic Nerve Cross Section from Group A Showing Normal Myelinationed Axons. LFB Stain, X40. E: Photomicrographs of Optic Nerve Cross Section from Group B Showing Severe Axonal Demyelination. LFB Stain, X40. F: Photomicrographs of Optic Nerve Cross Section from Group D Showing Mild Axonal Demyelination. LFB Stain, X40. 
number (37.4 \pm 1.54$)$ was observed in the positive control group that received EMB alone, this result is consistent with earlier observations (Chung et al., 2009) [25]. They reported that EMB induced optic neuropathy causes vacuolar changes in the optic nerve. No significant $(P>$ 0.05) difference was found between the number of vacuoles in the positive control group and; the group treated with EMB and $25 \mathrm{mg} / \mathrm{kg}$ TE. However, there was significant difference $(P<0.05)$ when the number of vacuoles of negative control group, and the groups treated with EMB and $50 \mathrm{mg} / \mathrm{kg}$ TE and; EMB and $100 \mathrm{mg} / \mathrm{kg}$ TE were compared to those of the positive control (EMB only) group.

Vacuolations show axonal degeneration induced by EMB (Zubair et al., 2009) [26]. The exact mechanism how EMB induced vacuoles are formed has not been confirmed (Fonkem et al., 2013) [27]. However the suggested mechanism is related to the chelating effects of EMB and its metabolites that interfere with several mitochondrial metal containing enzymes (Guillet et al., 2010) [28], such as the iron containing complex I and copper containing complex IV (Kinoshita et al., 2012) [11]. This interrupts oxidative phosphorylation and mitochondrial function leading to adenosine triphosphate (ATP) depletion (Wang et al., 2012) [3], generation and accumulation of reactive oxygen species (ROS) that cause oxidative stress in the optic nerve (Areti et al., 2014) [29]. The resultant effect is anaerobic glycolysis, forming lipids inside the axon that microscopically appear like vacuoles (Chen et al., 2015) [7]. It is speculated that Lantana trifolium protected the optic nerve against EMB induced vacuolation by interfering with this mechanism.

The protective potential of Lantana trifolium against EMB induced optic nerve vacuolations is probably as result of its anti-oxidative activity which is attributed to its high amounts of phenols (Salabarría et al., 2009) [30]. This is done through blocking the formation of ROS and scavenging them once they have been formed by donating electrons to the highly reactive free radicals (Perumal et al., 2012)
[31]. This results into formation of stable compounds and thus reduction of oxidative stress in the optic nerves. In another study, caffeic acid phenethyl ester, a phenolic compound found in plants was found to significantly decrease vacuolation by preventing oxidative stress in the optic nerve of EMB treated rats (Uzar et al., 2014) [32].

Ethambutol induced severe demyelination of the axons as observed in the positive control (EMB only) and the group treated with EMB and $25 \mathrm{mg} / \mathrm{kg}$ TE groups (fig.7). The result of our investigation is consistent with the findings of (Han et al., 2015) [33]. However, Zubair et al., (2009) [26] reported differing results, they did not observe demyelination of the axons after four weeks of EMB treatment. This difference could be as a result of 1 week difference in the duration of the experiments. Demyelination in the groups treated with EMB and $50 \mathrm{mg} / \mathrm{kg}$ TE and; EMB and $100 \mathrm{mg} / \mathrm{kg}$ TE was mild (fig. 8); suggesting that Lantana trifolium extract effectively protected the optic nerve against EMB induced axonal demyelination at doses of $50 \mathrm{mg} / \mathrm{kg}$ and $100 \mathrm{mg} / \mathrm{kg}$.

Ethambutol toxicity damages myelin, a fatty acid layer produced by the oligodendrocytes that surrounds optic nerve axons (Fancy et al., 2011) [34]. Myelin is responsible for fast transmission of signals through the nerves (Crawford et al., 2014) [35]. Damage to the myelin sheath results into progressive axonal loss. A similar mechanism as described above of EMB metal chelating effect has been suggested as well for its induced axonal demyelination (Guillet et al., 2010) [28]. Other studies reported that EMB toxicity induces demyelination through inhibition of phosphorylation by cyclic adenosine monophosphate (AMP) dependent protein kinase-A (Griffith et al., 2005) [36]. This is the same mechanism for phosphorylating myelin basic proteins (Chan and Kwok, 2006) [37]. By compromising respiratory function, a major consequence of reactive oxygen species accumulation may generate some compensatory proliferation of mitochondria in the endothelial and smooth muscle cells of optic 
nerve blood vessels (Osaguona et al., 2014) [38]. These changes result into vascular inflammation and thus a reduced blood supply to the nerve tissue that precedes myelin breakdown (Rasool et al., 2015) [10].

Since oligodendrocytes are preserved in the early stages of demyelination, the myelin sheaths around the optic nerve axons can be reconstructed after eliminating the cause of the myelin damage (Young et al., 2013) [39]. Therefore it is possible that Lantana trifolium ethanolic extract protected the optic nerve against EMB induced demyelination by restoring oxidative phosphorylation and inhibiting inflammation. The plant's anti-oxidative activity has already been mentioned in previous studies (Imbenzi et al., 2014) [18]. Lantana trifolium ethanolic extract is known for its antiinflammatory activity attributed to the high flavonoid content (Silva et al., 2005) [17]. The mechanism of how it prevents inflammation has not been studied sufficiently. However Julio et al., (2010) [40] reported that Lantana trifolium inhibits inflammation by reducing histamine release.

In conclusion, Lantana trifolium ethanolic extract had a dose dependent neuroprotective potential against ethambutol (EMB) induced histological changes in the optic nerve. The potential of Lantana trifolium ethanolic extract to protect the optic nerve against EMB induced changes could be as a result of its antioxidative and anti-inflammatory activities. These have been attributed to the high amounts of phenols and flavonoid, components of Lantana trifolium phytochemicals.

We recommend that further Studies using immunohistochemical techniques to evaluate EMB induced histological changes in the optic nerve are carried out. Studies should be conducted to establish Lantana trifolium's exact phytochemical component and mechanism of action of responsible for its neuroprotective potential.

\section{Competing interest}

Authors declare that there is no conflict of interests regarding the publication of this paper.

\section{REFERENCES}

1. Biadglegne, F., Tessema, B., Sack, U., \& Rodloff, A. C. 2014. Drug resistance of Mycobacterium tuberculosis isolates from tuberculosis lymphadenitis patients in Ethiopia. Indian J of Med Res, 140(JUL), 116-122.

2. Lacoma, A., Molina-Moya, B., Prat, C., Pimkina, E., Diaz, J., Dudnyk, A., Dominguez, J. 2015. Pyrosequencing for rapid detection of Mycobacterium tuberculosis second-line drugs and ethambutol resistance. Diagnostic Microbiology and Infectious Disease, 83(3), 263-269.

3. Wang, W., Yang, H., \& Xhang, X. L. 2012. Present status of ethambutol-induced optic neuropathy. Zhonghua Yan Ke Za Zhi, 48(2), 184-188.

4. Forbes, M., Kuck, N. A., \& Peets, E. A. 1962. Mode of action of ethambutol. J of Bacteriology, 84, 1099-1103.

5. Holla, S. N., Mohan Babu Amberkar, V., Rajeshkrishna Bhandary, P., Meena Kumari, K., \& Janardhanan, M. 2015. Cycloserine induced late onset psychosis and ethambutol induced peripheral neuropathy associated with MDR-TB treatment in an Indian patient- $A$ rare case report. J of Clinical and Diagnostic Res, 9(2), FD01-FD03.

6. Garg, P., Garg, R., Prasad, R., \& Mishra, A. K. 2015. A prospective study of ocular toxicity in patients receiving ethambutol as a part of directly observed treatment strategy therapy. Lung India : Official Organ of Indian Chest Soc, 32(1), 16-19.

7. Chen, S. C., Lin, M. C., \& Sheu, S. J. 2015. Incidence and prognostic factor of ethambutolrelated optic neuropathy: 10-year experience in southern Taiwan. Kaohsiung J of Med Sci, 31(7), 358-362. 
8. Bourne, R. R. A., Stevens, G. A., White, R. A., Smith, J. L., Flaxman, S. R., Price, H., Taylor, H. R. 2013. Causes of vision loss worldwide, 1990-2010: A systematic analysis. The Lancet Global Health, 1(6).

9. Palomino, J. C., \& Martin, A. 2014. Drug Resistance Mechanisms in Mycobacterium tuberculosis, Antibiotics; 317-340.

10. Rasool, M., Malik, A., Manan, A., Aziz, K., Mahmood, A., Zaheer, S., Karim, S. 2015. Determination of potential role of antioxidative status and circulating biochemical markers in the pathogenesis of ethambutol induced toxic optic neuropathy among diabetic and non-diabetic patients. Saudi J of Bio Sci, 22(6), 739-743.

11. Kinoshita, J., Iwata, N., Maejima, T., Kimotsuki, T., \& Yasuda, M. 2012. Retinal function and morphology in monkeys with ethambutol-induced optic neuropathy. Invest Ophth and Visual Sci, 53(11), 7052-7062.

12. Jeanjean, L., \& Dupeyron, G. 2014. Non-organic visual loss. J Français D'ophtalmologie, 37(5), 415-20.

13. Yang, H. K., Park, M. J., Lee, J. H., Lee, C. T., Park, J. S., \& Hwang, J. M. 2016. Incidence of toxic optic neuropathy with low-dose ethambutol. International J of Tuberculosis and Lung Disease, 20(2), 261-264.

14. Nalubega, R., Kabasa, J. D., Olila, D., \& Kateregga, J. 2011. Antibacterial activity and phytochemical screening of eleven plants used as poultry ethnomedicines in southern Uganda. Agricultural J, 6(6), 303-309.

15. Schemske, D. W. 1976. Pollinator Specificity in Lantana camara and L. trifolia (Verbenaceae). Biotropica, 8(4), 260-264.

16. Ocheng, F., Bwanga, F., Joloba, M., Borg-Karlson, A.-K., Gustafsson, A., \& Obua, C. 2014. Antibacterial activities of extracts from Ugandan medicinal plants used for oral care. Jof Ethnopharmacology, 155(1), 852-855.

17. Silva, G. N., Martins, F. R., Matheus, M. E., Leitão, S. G., \& Fernandes, P. D. 2005. Investigation of anti-inflammatory and antinociceptive activities of Lantana trifolia. J of Ethnopharmacology, 100(3), 254-259.

18. Imbenzi, P. S., He, Y., Yan, Z., Osoro, E. K., \& Cheplogoi, P. K. 2014. Chemical Constituents in Extracts from Leaves of Lantana trifolia and Their In Vitro Anti-oxidative Activity. Chinese Herbal Med, 6(3), 242-246.

19. National Research Council. 2010. Guide for the care and use of laboratory animals. Lab Animals; 66.

20. Luque de Castro, M. D., \& Priego-Capote, F. 2010. Soxhlet extraction: Past and present panacea. Jof Chromatography A; 1217(16).

21. Ninsiima Herbert Izo, Kirimuhuzya Claude, Okello Samuel. 2016. Anticonvulsant and toxicity effects of ethanolic extract of Thevetia Peruviana (Pers.) leaves. Int J of Ethnopharmacolog; 2(1), pp. 007-013.

22. Heffner, T. G., Hartman, J. a, \& Seiden, L. S. 1980. A rapid method for the regional dissection of the rat brain. Pharmacology, Biochemistry, and Behavior, 13, 453-456.

23. Kiernan, J., Lillie, R., Pizzolato, P., Donaldson, P., Llewellyn, B., Puchtler, H., Waldrop, F. 2010. Haematoxylin Eosin (H\&E) staining Protocols Online.

24. Sadun, A. A. 2012. Mitochondrial Optic Neuropathies: Toxic / metabolic. Annual Meeting Syllabus, 71-76.

25. Chung, H., Yoon, Y. H., Hwang, J. J., Cho, K. S., Koh, J. Y., \& Kim, J. G. 2009. Ethambutolinduced toxicity is mediated by zinc and lysosomal membrane permeabilization in cultured retinal cells. Toxicology and Applied Pharmacology, 235(2), 163-170.

26. Zubair, M., Tahir, M., Sheikh, T. H., Samee, K. P. L. W., \& Munir, B. 2009. Prevention of 
ethambutol induced changes by memantine in optic nerve of rabbit. Biomedica, 25, 19-23.

27. Fonkem, E., Skordilis, M. A., Binkley, E. M., Raymer, D. S., Epstein, A., Arnold, W. D., Lawson, V. H. (2013). Ethambutol Toxicity Exacerbating the Phenotype Of CMT2A2. Muscle and Nerve, 48(1), 140-144.

28. Guillet, V., Chevrollier, A., Cassereau, J., Letournel, F., Gueguen, N., Richard, L., Bonneau, D. 2010. Ethambutol-induced optic neuropathy linked to OPA1 mutation and mitochondrial toxicity. Mitochondrion, 10(2), 115-124.

29. Areti, A., Yerra, V. G., Naidu, V., \& Kumar, A. 2014. Oxidative stress and nerve damage: Role in chemotherapy induced peripheral neuropathy. Redox Biology, 2, 289-95.

30. Salabarría, I. S., Díaz, A. B. V., Morera, T. G., Turro, D. G., \& Pérez, T. H. G. 2009. Estudio fitoquímico y de actividad alelopática del extracto de $\mathrm{n}$-hexano del follaje de Lantana trifolia $\mathrm{L}$. (Spanish). Revista CENIC Ciencias Quimicas, 40(1), 33-37.

31. Perumal, P. C., Sophia, D., Raj, C. A., Ragavendran, P., Starlin, T., \& Gopalakrishnan, V. K. 2012. In vitro antioxidant activities and HPTLC analysis of ethanolic extract of Cayratia trifolia (L.). Asian Pacific J of Tropical Disease, 2(SUPPL2).

32. Uzar, E., Varol, S., Acar, A., Firat, U., Basarslan, S. K., Evliyaoglu, O., Gökalp, O. 2014. Assesment the role of oxidative stress and efficacy of caffeic acid phenethyl ester (CAPE) on neurotoxicity induced by isoniazid and ethambutol in a rat model. European Review for Med and Pharmacological Sci, 18(19), 2953-9.

33. Han, J., Byun, M. K., Lee, J., Han, S. Y., Lee, J. B., \& Han, S. H. (2015). Longitudinal analysis of retinal nerve fiber layer and ganglion cell-inner plexiform layer thickness in ethambutol-induced optic neuropathy. Graefes Arch Clin Exp Ophthalmol, 253(12), 2293-2299..

34. Fancy, S. P. J., Chan, J. R., Baranzini, S. E., Franklin, R. J. M., \& Rowitch, D. H. 2011. Myelin Regeneration: A Recapitulation of Development? Annual Review of Neuroscience, 34(1), 21-43.

35. Crawford, A. H., Stockley, J. H., Tripathi, R. B., Richardson, W. D., \& Franklin, R. J. M. 2014. Oligodendrocyte progenitors: Adult stem cells of the central nervous system? Expt Neurology; 260, pp50-55.

36. Griffith, D. E., Brown-Elliott, B. A., Shepherd, S., McLarty, J., Griffith, L., \& Wallace, R. J. 2005. Ethambutol ocular toxicity in treatment regimens for Mycobacterium avium complex lung disease. Am J of Resp and Critical Care Med, 172(2), 250-253.

37. Chan, R. Y. C., \& Kwok, A. K. H. 2006. Ocular toxicity of ethambutol. Hong Kong Med J; 12 (1).

38. Osaguona, V. B., Sharpe, J. a, Awaji, S. a, Farb, R. I., \& Sundaram, A. N. E. 2014. Optic chiasm involvement on MRI with ethambutol-induced bitemporal hemianopia. J of Neuro-Ophth: 34(2), 155-8.

39. Young, K. M., Psachoulia, K., Tripathi, R. B., Dunn, S. J., Cossell, L., Attwell, D., Richardson, W. D. 2013. Oligodendrocyte dynamics in the healthy adult CNS: Evidence for myelin remodeling. Neuron, 77(5), 873-885.

40. Julio, L. de S., Leito, S. G., Lotti, C., Picinelli, A. L., Rastrelli, L., Fernandes, P. D., Leito, G. G. (2010). Flavones and phenylpropanoids from a sedative extract of Lantana trifolia $L$. Phytochemistry, 71(2-3), 294-300. 